\title{
THE DIFFERENCES BETWEEN ACQUA AND CONVENTIONAL DENTAL IMPLANTS
}

\author{
Esraa F. Shams ${ }^{1} B D S$, Ahmed A. Sharara ${ }^{2}$ Phd, Ahmed O. Sweedan ${ }^{3}$ Phd
}

ABSTRACT

INTRODUCTION: Missing teeth were a problem in the 1950s and 1960s till the real use of titanium dental implants to restore teeth. Scientists tried hard over many years to improve the surface treatment of the dental implant in order to improve the function and longevity of it and to reduce the chances of its failure. New materials and techniques are used to change the surface texture, component, and its surface energy. OBJECTIVES: Evaluation of the delayed placement of ACQUA dental implant versus the conventional type for replacement of maxillary premolar teeth.

MATERIALS AND METHODS: Study was conducted on 14 patients. Patients were divided equally into two groups. Group "A” patients received ACQUA Alvium Neodent dental implant while group "B” patients received conventional Alvium dental implants. All Patients had missing maxillary premolars teeth. Patients were between 27- 48 years old. All patients were operated under local anesthesia. The surgical stent was checked for proper seating in the planned site of the dental implant. A full thickness mucoperiosteal flap was performed. Follow-up was done daily for the first week, then weekly for the first month, then monthly for six months.

RESULTS: Clinically no edema was shown in all patients. Other clinical parameters were recorded during the follow-up period as the gingival index, implant stability, and presence or absence of infection. Radiographic results showed that there was a significant difference between ACQUA and conventional Alvium dental implant which proved the higher initial stability of ACQUA Alvium Implants compared to conventional ones. Marginal bone height did not show any significant difference between ACQUA implants and conventional implants.

CONCLUSIONS: ACQUA dental implant showed more primary stability than conventional Alvium implant. Additionally, ACQUA showed more bone intensity compared to the other type.

KEYWORDS: ACQUA dental implant, Conventional Alvium, Comparison, Osstell, CBCT.

1. General dentist at Fawzy Moaaz pediatric hospital, the ministry of health, Egypt.

2. Professor of Oral and Maxillofacial Surgery, Faculty of Dentistry, Alexandria University, Egypt.

3. lecturer of Oral and Maxillofacial Surgery, Faculty of Dentistry, Alexandria University, Egypt

\section{Corresponding author}

Name: Esraa F. Shams

E-mail:dr.esraa_mfs@yahoo.com

\section{INTRODUCTION}

By the discovery of the dental implant, scientists faced a new challenge regarding increasing the fixation of the dental implant into the bone (osseointegration). That raised many questions raised regarding dental implant like; how the body will accept the new device?, what type of modifications that need to be done to improve the body acceptance for the implant, and how to reduce the time interval between the surgery and the placement of the final restorations (1)?.

However, the new era of surface treatment was showed up to answer all these questions and to help scientists in solving these issues. Starting with machining of the dental implant passing through anodic oxidation, grit-blasting, acid etching, combination of both acid etch and grit-blasting ,plasma spraying, calcium phosphate coating, biomemic calcium phosphate, hydroxyl appetite coating, nanotechnology, silica gel, and the latest trend till now dipping the dental implant in ACQUA solution (2).

Since the osseointegration of the dental implant in the jaw bone is a matter of concern, the surface treatment and the surface energy were studied to get the maximum benefits. The surface energy of the dental implant can be divided into hydrophilic and hydrophobic surface depending on the surface treatment and the charges of the surface. The more positive charges on the implant surface, the more hydrophilic the surface is. This will help in attracting some plasma proteins, electrolytes, and growth factors to establish osseointegration (3).

Primary stability of the dental implant is the primary factor affecting the osseointegration. This stability is provided mechanically by macro-retentions engaging in the bony walls of the implant bed. During healing, it will be replaced by a biological bonding of newly formed bone to the implant surface and which termed secondary stability (4).

The changes of the tissue during the integration process, such as bone modeling and remodeling at the implant-bone interface, may determine the degree of secondary implant stability (5).

Recently, a new super hydrophilic implant was commercially available, ACQUA® Alvium (Neodent, Curitiba, PR, Brazil), which is produced by a similar method than SL Active, resulting in similar microroughness and contact angle. The ACQUA dental implant has a NeoPoros surface as the conventional Alvium one except it comes immersed in an aquatic solution which is an isotonic solution of $0.9 \%$ sodium chloride that gives the hydrophilic property of the surface which attracts the plasma proteins, osteoblast cell, growth factors and electrolytes from the interstitial fluid (6). 
ACQUA implant combined the surface treatment and the hydrophilicity to increase the osseointegration and the primary stability (6).

Therefore, the present study was designed to evaluate clinically and radiographically the difference between the Acqua Alvium dental implant and the conventional Alvium dental implant.

\section{MATERIALS AND METHODS \\ Informed consent}

Appropriate institutional ethical clearance from the Alexandria University faculty of dentistry Ethical Committee and written informed consent from the patients were obtained. All patients were informed about the aim of the designed study and the steps of the procedure with the time interval.

\section{Patient selection and evaluation}

This study was conducted on 14 patients (eight females and six males), with ages between $20-50$ years old. All patients had missing maxillary premolar teeth selected from the outpatient clinic of the Oral and Maxillofacial surgery department, Faculty of Dentistry, Alexandria University. Patients were divided into two groups (group A Vs. group B). Group A patients received ACQUA Alvium dental implants, while Group B patients received conventional Alvium dental implant.

The inclusion criteria were; patients had good oral hygiene, sufficient bone volume, and adequate vertical dimension. The exclusion criteria were; all patients with periodontal disease or active infection, inadequate interocclusal space, bruxism or clenching, heavy smokers, pregnant women, and patients with local factors or medically compromised conditions such as uncontrolled Diabetes Millets, osteoporosis, organ transplantation, or current chemotherapy or radiotherapy.

The preoperative clinical examinations were performed for all patients. Patients data were collected including; name, gender, age, contact information, medical and dental history. Clinical examination was performed intra-orally and extra-orally. Additionally, the oral mucosa at the site of the planned implant was examined for color, texture, firmness, and thickness. The occlusion and remaining teeth were observed.

Also, preoperative evaluation for all patients included panoramic X-ray and cone beam computerized tomography (CBCT) that was used to evaluate the recipient sites` bone height and width, as well as to determine the relationship to other structures such as maxillary sinus and adjacent teeth (Figure 1).

The resonance frequency analysis test (OSSTELL) was used twice in this study, at the time of surgery and at the time of abutment placement, to determine the primary and the secondary stability respectively.

\section{Materials and equipment}

Fourteen ACQUA and conventional Alvium NEODENT dental implants with unique surface treatment were used equally. Each implant formed of 2 pieces with different diameters 3.5, 4.3 and different lengths 8, 10, 11.5 were used in this study.

The ACQUA dental implant had the same NeoPoros surface as the conventional type and immersed in an aquatic solution which was an isotonic solution of $0.9 \%$ sodium chloride.

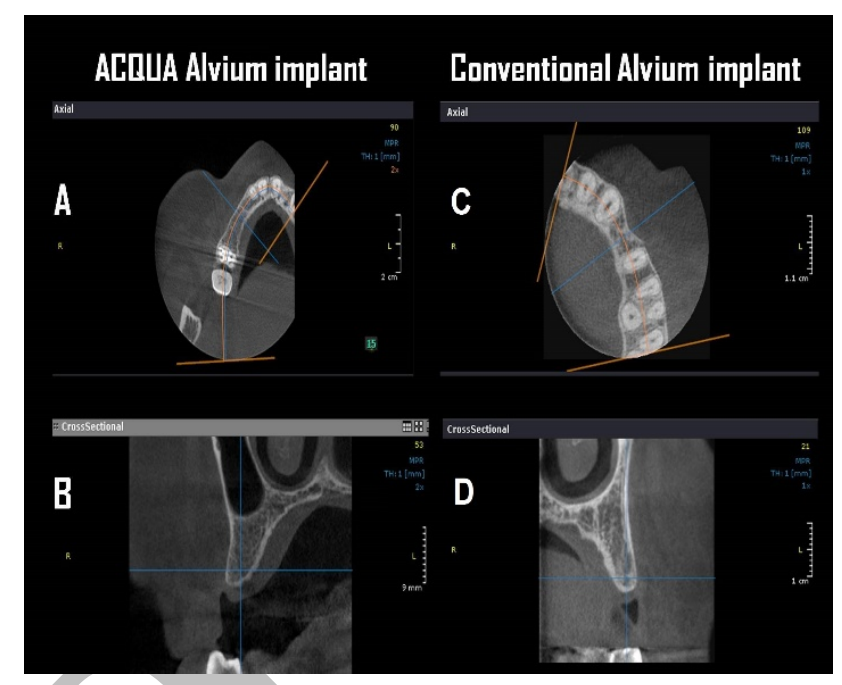

Figure (1): Preoperative CBCT for ACQUA and Conventional Dental implant. A. For Axial cut of ACQUA Alvuim dental implant. B. Cross section for ACQUA alvuim dental implant. C. For Axial cut of the Conventional alvuim dental implant. D. Cross section for the Conventional alvuim dental implant.

The Alvium NEODENT dental implant was characterized by a tapered implant body which made the drilling and placement more comfortable. The apex contained cutting chamber designed to optimize the secondary stability. Double conical trapezoidal threads designed with interspace of $0.6 \mathrm{~mm}$ to increase the anchorage of the dental implant in the bone and to increase primary stability. The conventional dental implant had a NeoPoros surface which was created using an abrasive particle jet concept with controlled grain oxides, followed by acid etching that formed uniform cavities in the implant surface.

\section{Surgical procedure}

All patients were instructed to rinse their mouths thoroughly before surgery using a $0.12 \%$ chlorhexidine mouthwash solution (Hexitol: Arabic drug company, ADCO, Egypt) for 30 sec. Patients were operated under local anesthesia Mepivacaine $\mathrm{HCl} 2 \%$ with levonordefrin 1:2000 (Mepecain-L, $1.8 \mathrm{ml}$ carpule. Alexandria co. Egypt). The full-thickness mucoperiosteal flap was reflected using a periosteal elevator at the site of the placement of the dental implant. The motor was adjusted to the low speed of 1000 rpm, high torque and internal irrigation using normal saline to maintain the vitality of the bone.

Moreover, the surgical stent was placed in its position. The first drill was used to mark the placement site of the dental implant to establish the correct position, depth, and the alignment based on the CBCT measurement. Sequential drilling (alvium 2, alvium 3.5 or alvium 2, alvium 3.5, alvium 4.3 based on the implant diameter) was done using the standard drill then the final drill to widen the osteotomy site according to the implant size. A parallel pin was used in the osteotomy site to confirm the position and the angulation of the osteotomy site. Decapping and extraction of the implant from the pack and the ACQUA solution.

In group A patients the ACQUA Alvium dental implant was inserted into the prepared site using Neodent Ratchet with insertion torque of 30-50 Ncm. Smart pegTM specific for Alvium Neodent was attached to the internal hex of the dental implant. Osstell ISQ measured the primary stability of the dental implant by holding the measurement probe close to the top of the Smart pegTM in buccolingual and 
mesiodistal directions. The smart peg was then removed, and the cover screw was placed. Finally, the flap was repositioned and sutured using 3/0 black silk suture (Figure 2).

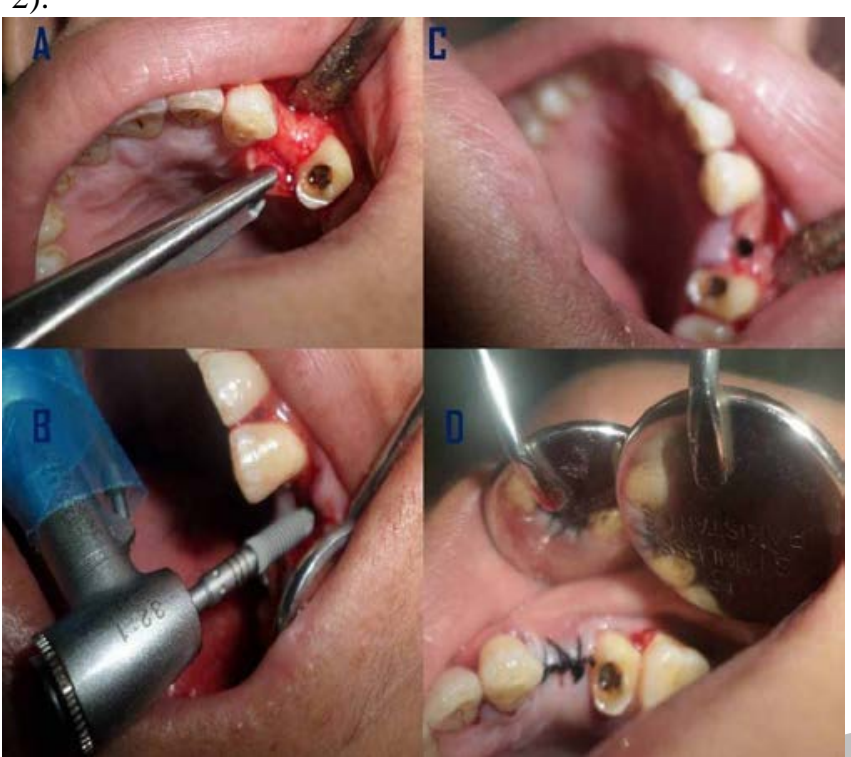

Figure (2): Flap procedures for Conventional Alvuim dental implant. A. Full thickness flap of the surgical site, B. During placement of the dental implant, C. After placement of the dental implant, D. Suturing of the flap.

In group B patients the conventional Alvium Neodent dental implant inserted into the prepared site using Neodent Ratchet with insertion torque of 30-50 Ncm. Smart pegTM specific for Alvium Neodent was attached to the internal hex of the dental implant. Osstell ISQ measured the primary stability of the dental implant by holding the measurement probe close to the top of the smart peg in both buccolingual and mesiodistal directions. The smart peg was then removed, and the cover screw was placed. Finally, the flap was repositioned and sutured using $3 / 0$ black silk suture (Figure 3).

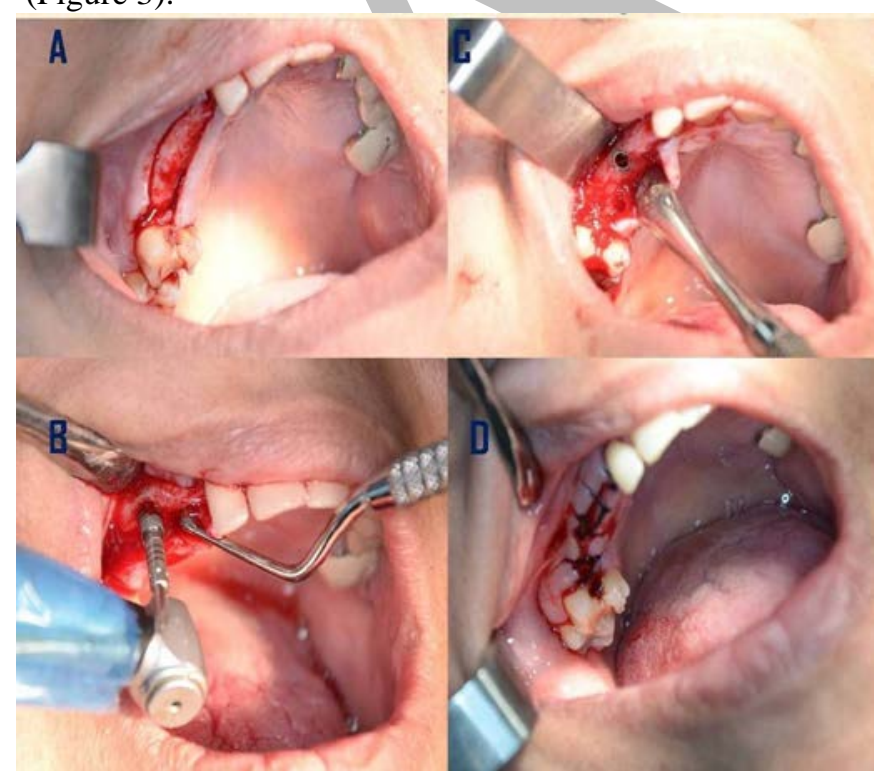

Figure (3):Flap procedures for ACQUA dental implant. A. Full thickness flap of the surgical site, B. During placement of the dental implant, C. After placement of the dental implant, D. Suturing of the flap.
The stability of the dental implant was examined twice in this study. The primary stability at the time of surgery and secondary stability before placing the abutment, both were measured using the OSSTELL. For measuring the primary stability, the smart pegs were attached to the internal hex of the implant fixture which had been applied to the bone already using an integrated screw (Figure 4).

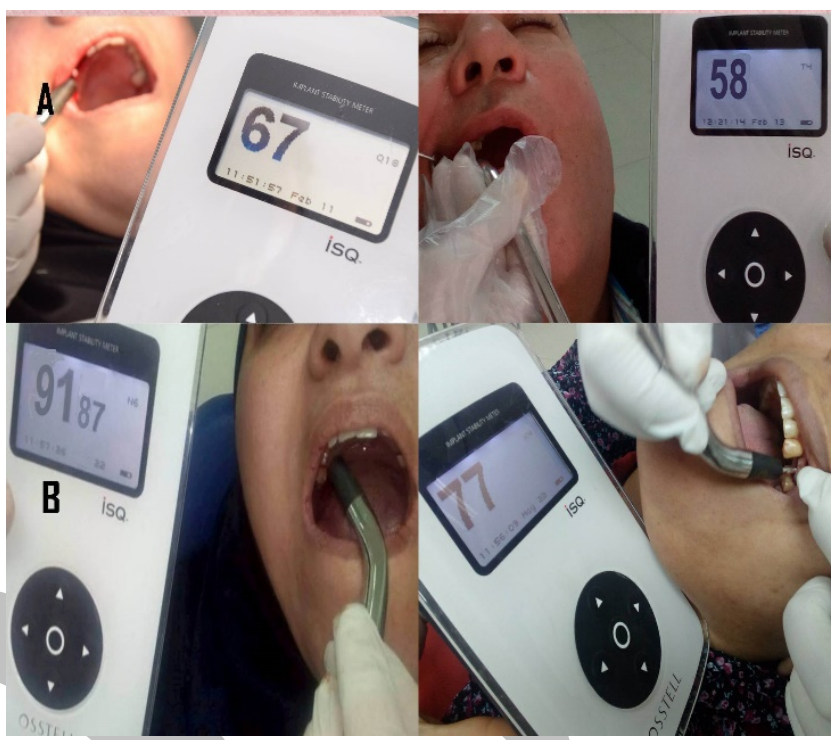

Figure (4): Stability of the dental implant using Osstell. A. Showed Primary Stability, B. Showed the stability after four months. Right Side for ACQUA dental implant. The left side for Conventional Alvium dental implant.

The probe on the handheld instrument initiated a magnetic pulse which allowed the smart peg to vibrate and made the implant vibrates as well measuring the resistance of implant within the bone to vibrate.

The implant stability measured at two levels buccolingual and mesiodistal directions, the results were displayed on the screen of the device as a value ranging from 0-100 and measured by ISQ implant stability quotient. The more substantial the amount, the more stable the implant would be.

\section{Postoperative evaluation}

Post-operative instructions included the application of cold fomentation extra orally for the first 24 hours and warm mouthwash on the next day and oral hygiene instruction. The sutures were removed after 1-week post-operatively.

Post-operative medications included: Amoxicillin 875 Clavulanic acid 125 tablets antibiotic every 12 hours for 7 days (Augmentin: GlaxoSmithKline, UK) Non-steroidal anti-inflammatory drug every 8 hours for 3 days (Ibuprofen 400mgtab), Chlorohexidine HCL $0.12 \%$ (Hexitol: Chlorhexidine $125 \mathrm{mg} / 100 \mathrm{ml}$, concentration $0.125 \%$ : Arabic drug company, ADCO) as a mouthwash used starting from the 2nd day after surgery, used for 2 weeks 3 times daily.

\section{Post-operative follow-up:}

Clinically:

Healing of the soft tissue was evaluated after one week. Presence of pain or infection $(6,7)$. The pain was assessed using the numeric rating scale (NRS-11) $(8,9)$. The Loe and Silness' Gingival Index was used to determine the condition of the gingiva $(10,11)$.

Stability of the dental implant was measured using the Osstell device after implant placement then after 4 months. 


\section{Radiographically:}

All patients were evaluated at the time interval of 3 and 6 months postoperatively using CBCT. The location, the parallelism of the implant to the roots of adjacent teeth and the success of the implant with no signs of bone resorption were evaluated using CBCT, which focused on:-

A- Bone density and the osseointegration around the dental implant: The virtual implant was selected from the database of the On-demand 3D software and placed at the site of the implant, and a mean of bone density was measured automatically. The virtual implant matched the same implant used in this study which is Alvium Neodent dental implant.

B- Marginal bone level: Measured using the linear measurement system supplied in the On-demand3D software. The mesial and distal bone hight level changes were measured at two times intervals 3 and 6 months postoperatively (Figure 5). The distance between the top of the platform of the dental implant and the first point of boneimplant contact was used to represent the bone defect.

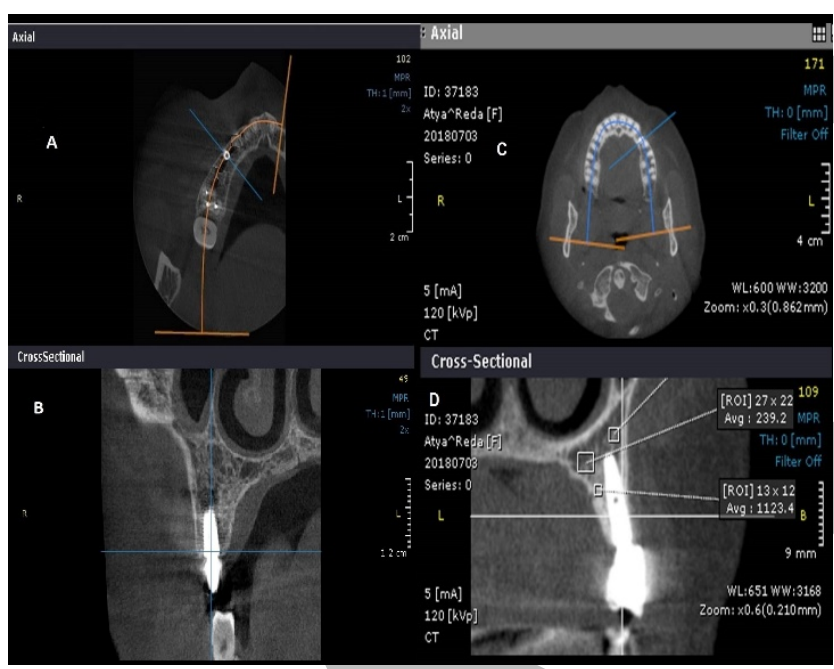

Figure (5): Showed CBCT postoperatively after six months. Right side for ACQUA dental implant. Left side for the conventional alvuim dental implant.

\section{Statistical Analysis}

Data were fed to the computer and analyzed using IBM SPSS software (Package version 23.0. IBM Corporation, 1 New Orchard Road, Armonk, New York, United States). Quantitative data were described using range (minimum and maximum), mean, and standard deviation. The distributions of quantitative variables were tested for normality using the Kolmogorov-Smirnov test. If it reveals normal data distribution, parametric tests were applied. If the data were abnormally distributed, non-parametric tests were used. For abnormally distributed data, a comparison between two independent populations was made using appropriate parametric tests. The significance of the obtained results was judged at the $5 \%$ level.

\section{RESULTS}

\section{Clinical Evaluation}

All the patients have been operated under the local anesthesia. The full-thickness mucoperiosteal flap had been done for all the patients. ACQUA and conventional dental implants were used. No complications had been recorded during the operation.
All the patients were examined periodically for six months. All the patients completed their scheduled follow up. Healing was uneventful in all cases with no postoperative infection. Other clinical evaluations had been assessed during the follow-up period including pain index, gingival index, implant mobility, and primary and secondary implant stability tests.

\section{I- Resonance frequency analysis device (OSSTELL)}

The implant stability measurement was examined at the time of insertion of the implants and at the time of abutment placement after 4 months for the two groups of patients using the resonance Frequency Analysis via the Osstell ISQ system, where each implant was measured in two directions mesiodistally and buccolingually, and the average value was taken.

The comparison between ACQUA and conventional Alvium was made from the following perspectives:-

\section{A- Primary Stability}

Further analysis was conducted, using an independent t-test to examine the difference between ACQUA and conventional Alvium. Results showed that an ACQUA implant was better than conventional Alvium according to primary Stability (Table 1) (Figure 6).

Table (1): Comparison between different groups according to Osstell reading $(\mathrm{N}=14)$, and Comparison between the two studied groups (ACQUA Vs. Conventional) according to the duration

\begin{tabular}{|c|c|c|c|c|c|}
\hline $\begin{array}{l}\text { Primary } \\
\text { stability }\end{array}$ & ACQUA & $\begin{array}{c}\text { Conventional } \\
\text { Alvium }\end{array}$ & df & $\mathbf{T}$ & $\mathbf{P}$ \\
\hline Mean & 55.79 & 53.29 & \multirow[t]{3}{*}{12} & \multirow[t]{3}{*}{3.098} & \multirow[t]{3}{*}{0.009} \\
\hline SD & 1.60 & 1.41 & & & \\
\hline SEM & 0.60 & 0.53 & & & \\
\hline $\begin{array}{l}\text { After } \\
4 \text { months }\end{array}$ & ACQUA & $\begin{array}{l}\text { Conventional } \\
\text { Alvium }\end{array}$ & df & $T$ & $\mathbf{P}$ \\
\hline Mean & 73.00 & 72.07 & \multirow[t]{3}{*}{12} & \multirow[t]{3}{*}{0.34} & \multirow[t]{3}{*}{0.74} \\
\hline $\mathrm{SD}$ & 5.13 & 5.15 & & & \\
\hline SEM & 1.94 & 1.94 & & & \\
\hline
\end{tabular}

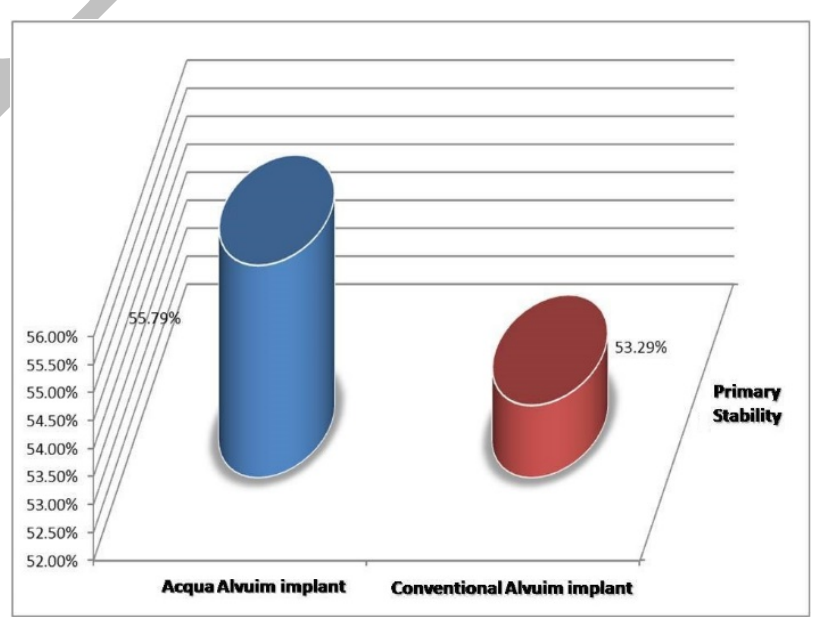

Figure (6): Showed the Mean of the comparison between ACQUA dental implant and Conventional Alvium Dental Implant.

\section{B- After four months}

Further analysis was conducted, using an independent t-test to examine the difference between ACQUA and Conventional Alvium. Results showed that there was no significant difference between ACQUA implants and Conventional Alvium implant after four months. However, 
these findings suggested that both dental implants had the same stability effect in four months.

\section{2- Radiographic Evaluation}

\section{I- Evaluation of bone density}

Bone density is defined as the means value expressed relating to bone minerals density in Hounsfield units in each pixel (12). Data were collected regarding mean peri-implant bone density values, standard deviation and percentage of changes at pre-operative, 3- months, and 6- months postoperative for both groups (Table 2)

From table 2 it is clear that there is no differences were reported between ACQUA dental implant and conventional dental implant

Table (2): Comparison between different groups according to $\mathrm{CBCT}(\mathrm{N}=14)$.

\begin{tabular}{|c|c|c|c|c|c|c|}
\hline Period & & ACQUA & $\begin{array}{c}\text { Conventional } \\
\text { Alvium }\end{array}$ & df & $\mathbf{T}$ & $\mathbf{P}$ \\
\hline \multirow{3}{*}{$\begin{array}{l}\text { Pre- } \\
\text { operative }\end{array}$} & Mean & 468.45 & 495.40 & \multirow{3}{*}{12} & \multirow{3}{*}{$\begin{array}{c}- \\
0.271\end{array}$} & \multirow{3}{*}{0.791} \\
\hline & SD & 149.39 & 216.73 & & & \\
\hline & SEM & 56.44 & 81.92 & & & \\
\hline \multirow[t]{3}{*}{3 months } & Mean & 694.43 & 668.78 & \multirow[t]{3}{*}{12} & & \multirow[t]{3}{*}{0.806} \\
\hline & $\mathrm{SD}$ & 190.84 & 190.82 & & & \\
\hline & SEM & 72.14 & 72.13 & & & \\
\hline \multirow[t]{3}{*}{6 months } & Mean & 791.34 & 755.61 & \multirow[t]{3}{*}{12} & 0.372 & \multirow[t]{3}{*}{0.717} \\
\hline & SD & 181.18 & 178.40 & & & \\
\hline & SEM & 68.48 & 67.43 & & & \\
\hline
\end{tabular}

\section{II- Marginal Bone Height}

The Marginal bone height was measured post-operatively, at three months and six months, at the mesial and distal side of the Dental implant for both groups (Group A \& B).

The comparison between ACQUA dental implant and conventional dental implant using independent - t-test was tested. Results showed that there is no significant difference between ACQUA and conventional dental implant at the marginal bone height (Table3).

Table (3): Comparison between the two studied groups (ACQUA Vs. Conventional) according to position and period

\begin{tabular}{|c|c|c|c|c|c|c|c|}
\hline Position & Period & & ACQUA & $\begin{array}{c}\text { Conventional } \\
\text { Alvium }\end{array}$ & df & $\mathbf{T}$ & $\mathbf{P}$ \\
\hline \multirow[t]{3}{*}{ Mesial } & \multirow{3}{*}{$\begin{array}{l}6 \\
\text { months }\end{array}$} & Mean & 0.11 & 0.15 & \multirow[t]{3}{*}{12} & \multirow{3}{*}{$-\overline{0.469}$} & \multirow[t]{3}{*}{0.647} \\
\hline & & $\mathrm{SD}$ & 0.16 & 0.20 & & & \\
\hline & & SEM & 0.06 & 0.08 & & & \\
\hline \multirow[t]{3}{*}{ Distal } & \multirow{3}{*}{$\begin{array}{l}6 \\
\text { months }\end{array}$} & Mean & 0.16 & 0.20 & \multirow[t]{3}{*}{12} & \multirow{3}{*}{$-\overline{0.365}$} & \multirow[t]{3}{*}{0.772} \\
\hline & & SD & 0.20 & 0.26 & & & \\
\hline & & SEM & 0.08 & 0.10 & & & \\
\hline
\end{tabular}

\section{DISCUSSION}

Preceding studies showed many factors were affecting the success of the dental implant starting $(13,14)$ from patient selection $(15,16)$ the dental implant itself $(17,18)$ the length of dental implant $(19,20)$, Diameter $(21,22)$, Type of bones $(23,24)$ Final restoration $(25,26)$ and Follow-up periods to complete this procedure successfully (27). All of these factors were considered in the current study.

This study investigated the evaluation of delayed placement of Acqua Alvium dental implant compared to the conventional Alvium type. All patients were non-smokers; patients were in between 27-48 years old.

This study conducted on 14 patients. All patients had missing maxillary premolars, and they were seeking for implant placement. All patients were from the Outpatient Clinic of the Oral and Maxillofacial Surgery Department, Faculty of Dentistry, Alexandria University. Pre-operative CBCT was done for each patient to evaluate the implant site, angulation of dental implant, length, the diameter of a dental implant, and bone density. The surgery was done, and additional follow-ups were conducted after different periods.

The clinical results of the current study showed that primary stability of ACQUA Alvium implant was better than conventional one statistically. In contrast, after the period of 4- months the statistical results did not show any differences in the secondary stability between ACQUA implant and conventional one. These findings suggested that the Acqua dental implant has the ability to show more stability compared to conventional alvuim dental implant. These findings in line with the similar findings of Sim CP et al, Bullis G et al and Kim DG et al (34-36) which showed clear differences between different types of dental implant and the effect of presence of the implant in aqueous solution. Nevertheless, there is no study as far as the authors know investigated the effect of primary stability for ACQUA dental implant.

Findings of the current study convey the success of dental implant which represented in the higher primary stability of ACQUA dental implant compared to the conventional one. These findings could be explained according to the factors which influence the stability of dental implant such as, the unique combination between the surface treatment of the dental implant and its hydrophilicity (28-31), length of the dental implant (1922,32-34), its design (2,35-37), surgical technique and drilling (38-40), bone type and Quality (32).

It might be that ACQUA dental implant can influence the hydrophilicity, surface treatment and surface energy because ACQUA was kept immersed in the aquatic solution that played an essential role in the stability of this type of dental implant. Nevertheless, the conventional alvium dental implant did not have the same ability as ACQUA in primary stability. Moreover, this phenomenon could be explained according to other studies to support the suggested interpretation. Interestingly, this pattern of results was absent after the follow-up of 4 months. Findings showed that there were no differences in stability between ACQUA dental implant and conventional alvium dental implant after four months. These findings suggested that both types of dental implants had the same degree of stability statistically.

Another Interestingly findings represented in radiographic results which showed a significant difference 
between ACQUA dental implant and conventional alvium dental implant, in bone density and marginal bone height. Results of bone density indicated that the bone density was statistically significant with follow up periods (preoperative, 3- months, and 6 months) in ACQUA dental implant, while there were no differences in the conventional alvium dental implant. These findings suggested that ACQUA dental implants can increase and enhance the bone density as compared to conventional alvium dental implants. These findings could be explained according to the properties of ACQUA dental implant compared to conventional alvium dental implant. Interestingly, these findings in line with the findings of previous studies (26, 29) which showed that some types of dental implant enhance the bone density depending on the implant treatment.

Results showed that the Properties of ACQUA dental implants played an essential role in enhancing and increasing the bone density. Interestingly, there was no difference between ACQUA, and the conventional alvium dental implant was reported in marginal bone height. These findings suggested that both dental implants that used in the current study have the same effect and influence from the marginal bone height point of view.

\section{CONCLUSION}

It's clear that ACQUA Alvium Neodent dental implant is better than the conventional Alvium Neodent dental implant as it gives higher primary stability so it can be used in cases of immediate implant placement. Additionally, ACQUA dental implant has a higher ability to increase and improve the bone density surrounding it. Both implants showed bone growth over the screw after four months.

\section{CONFLICT OF INTEREST}

The authors declare that they have no conflicts of interest.

\section{REFERENCES}

1- Brunski JB. Biomechanical factors are affecting the bone-dental implant interface. Clin Mater. 1992;10:153-201.

2- Elias CN, Oshida Y, Lima JHC, Muller CA. The relationship between surface properties (roughness, wettability, and morphology) of titanium and dental implant removal torque. J Mech Behav Biomed Mater. 2008;1:234-42.

3- Martin C, Thoms, G, Melo ACM, Fontúo FK. The peri-implant bone response following immediate implants placed in the esthetic zone and with immediate provisionalization--a case series study. Oral Maxillofac Surg. 2015;19:157-63.

4- Park JC, Lee JW, Kim SM, Lee JH. Implant stabilityMeasuring devices and randomized clinical trial for ISQ value change pattern measured from two different directions by magnetic RFA. InTech 2011;5:111-29.

5- Junker R, Dimakis A, Thoneick M, Jansen JA. Effects of implant surface coatings and composition on bone integration: a systematic review. Clin Oral Implants Res. 2009;20:185-206.

6- Ohnhaus EE, Adler R. Methodological problems in the measurement of pain: a comparison between the verbal rating scale and the visual analog scale. Pain. 1975;1:379-84.
7- Closs SJ, Barr B, Briggs M, Cash K, Seers K. A comparison of five pain assessment scales for nursing home residents with varying degrees of cognitive impairment. J Pain Symptom Manage. 2004;27:196205.

8- Carlsson AM. Assessment of chronic pain. I. Aspects of the reliability and validity of the visual analog scale. Pain. 1983;16:87-101.

9- Rodriguez CS. Pain measurement in the elderly: a review. Pain Manag Nurs. 2001;2:38-46.

10- Lobene RR, Weatherford T, Ross NM, Lamm RA, Menaker L. A modified gingival index for use in clinical trials. Clin Prev Dent.1986;8:3-6.

11- Löe $H$. The gingival index, the plaque index and the retention index systems. J Periodontol. 1967;38:6106.

12- Khan SN, Warkhedkar RM, Shyam AK. Analysis of the Hounsfield unit of human bones for strength evaluation. Procedia Mater. Sci. 2014;6:512-9.

13- Mendoza G, Mendoza DB, Aragao FJ, Cooper LF. Advancing dental implant surface technology--from micron-to nanotopography. Biomaterials. 2008;29:3822-35.

14- Misch CE, Perel ML, Wang HL, Sammartino G, Galindo-Moreno P, Trisi P, et al. Implant success, survival, and failure: the International Congress of Oral Implantologists (ICOI) Pisa consensus conference. Implant Dent. 2008;17:5-15.

15- Bain CA, Moy PK. The association between the failure of dental implants and cigarette smoking. Int J Oral Maxillofac Implants. 1993;8: 609-15.

16- Schmitt A, Zarb GA. The longitudinal clinical effectiveness of osseointegrated dental implants for single-tooth replacement. Int J Prosthodont. 1993;6: 197-202.

17- Esposito M, Coulthard P, Thomsen P, Worthington $\mathrm{HV}$. The role of implant surface modifications, shape, and material on the success of osseointegrated dental implants. A Cochrane systematic review. Eur J Prosthodont Restor Dent. 2005;13: 15-31.

18- Quesada-Garcia MP, Prados-Sanchez E, OlmedoGaya MV, Munoz-Soto E, Gonzílez-Rodrguez MP, Vallecillo-Capilla M. Measurement of dental implant stability by resonance frequency analysis: a review of the literature. Med Oral Patol Oral Cir Bucal. 2009;14:e538-e546.

19- Biaggi L, Cappelloni I, Di Girolamo M, Maceri F, Vairo G. The influence of implant diameter and length on stress distribution of osseointegrated implants related to crystal bone geometry: a three-dimensional finite element analysis. J Prosthet Dent. 2008;100:42231.

20- Himmlova L, Dostíloví T, Kícovsk A, Konvicakov S. Influence of implant length and diameter on stress distribution: a finite element analysis. J Prosthet Dent. 2004;91:20-5.

21- Miyamoto I, Tsuboi Y, Wada E, Suwa H, Iizuka T. Influence of cortical bone thickness and implant length on implant stability at the time of surgery-clinical, prospective, biomechanical, and imaging study. Bone. 2005;37:776-80.

22- Iplik H, Akaok K. Comparative evaluation of the effect of diameter, length and number of implants 
supporting three-unit fixed partial prostheses on stress distribution in the bone. J Dent. 2002;30:41-6.

23- Buser D, Schenk RK, Steinemann S, Fiorellini JP, Fox $\mathrm{CH}$, Stich $\mathrm{H}$. Influence of surface characteristics on bone integration of titanium implants. A histomorphometric study in miniature pigs. J Biomed Mater Res.1991;25:889-902.

24- Szmukler-Moncler S, Salama H, Reingewirtz Y, Dubruille $\mathrm{JH}$. The timing of loading and effect of micromotion on bone-dental implant interface: a review of the experimental literature. J Biomed Mater Res. 1998;43:192-203.

25- Garber DA. The esthetic dental implant: letting restoration be the guide. J Am Dent Assoc. 1995;126:319-25.

26- Balshi TJ, Wolfinger GJ. Dental implants in the diabetic patient: a retrospective study. Implant Dent. 1999;8:355-9.

27- Dixon DL, Breeding LC, Sadler JP, McKay ML. Comparison of screw loosening, rotation, and deflection among three implant designs. J Prosthet Dent. 1995;74:270-8.

28- O'Sullivan D, Sennerby L, Meredith N. Measurements comparing the initial stability of five designs of dental implants: a human cadaver study. Clin Implant Dent Relat Res. 2000;2:85-92.

29- Steigenga JT, Al-Shammari KF, Nociti FH, Misch CE, Wang HL. Dental implant design and its relationship to long-term implant success. Implant Dent. 2003;12:306-17.

30- dos Santos MV, Elias CN, Cavalcanti Lima JH. The effects of superficial roughness and design on the primary stability of dental implants. Clin Implant Dent Relat Res. 2011;13:215-23.

31- Geng JP, Tan KB, Liu GR. Application of finite element analysis in implant dentistry: a review of the literature. J Prosthet Dent. 2001;85:585-98.

32- Li T, Kong L, Wang Y, Hu K, Song L, Liu B, et al. Selection of optimal dental implant diameter and length in type IV bone: a three-dimensional finite element analysis. Int $\mathrm{J}$ Oral Maxillofac Surg. 2009;38:1077-83.

33- Petrie CS, Williams JL. Comparative evaluation of implant designs: influence of diameter, length, and taper on strains in the alveolar crest: A threedimensional finite-element analysis. Clin Oral Implants Res. 2005;16:486-94.

34- Sim CP, Lang NP. Factors influencing resonance frequency analysis assessed by Osstell mentor during implant tissue integration: I. Instrument positioning, bone structure, implant length. Clin Oral Implants Res. 2010;21:598-604.

35- Bullis G, Shah S. Implant Surface Treatments: A Literature Review. Inclusive Magazine 2018;5.

36- Kim DG, Shin MJ, Kim KH, Hanawa T. Surface treatments of titanium in aqueous solutions containing calcium and phosphate ions. Biomed Mater Eng. 1999;9:89-96.

37- Romeo E, Lops D, Margutti E, Ghisolfi M, Chiapasco M, Vogel G. Long-term survival and success of oral implants in the treatment of full and partial arches: a 7-year prospective study with the ITI dental implant system. Int J Oral Maxillofac Implants. 2004;19: $247-$ 59.
38- Misch CE. Dental Implant Prosthetics-E-Book. St. Louis: Elsevier Health Sciences, 2014.

39- Renvert S, Roo JansÑNer A, Claffey N. Nonsurgical treatment of peri-implant mucositis and periimplantitis: a literature review. J Clin Periodontol. 2008;35:305-15.

40- Lang NP, Wilson TG, Corbet EF. Biological complications with dental implants: their prevention, diagnosis and treatment Note. Clin Oral Implants Res. 2000;11:146-55.

1.

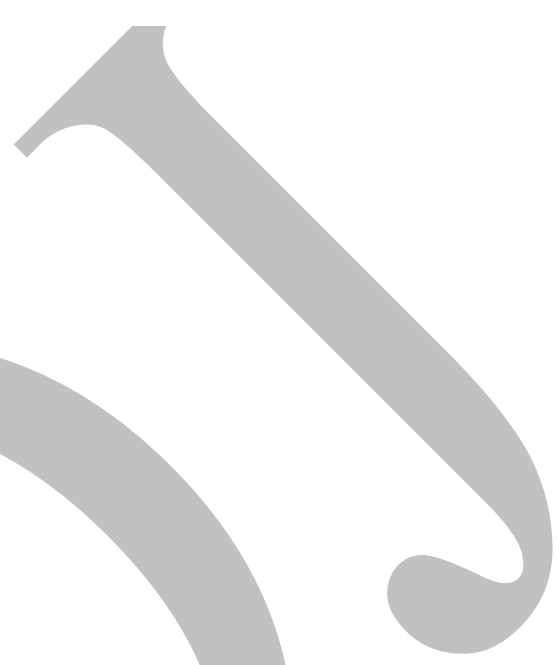

